\title{
Extensionalism and intensionalism in the realist-SSK 'debate'
}

\author{
EDWARD MARIYANI-SQUIRE \\ University of Western Sydney
}

\begin{abstract}
The 'strong programme' in the sociology of scientific knowledge (SSK) is based upon finitism and extensionalism. This article examines a critique of these bases. It is argued that David Tyfield's (2008; 2009) realist critique and his alternative intensionalist account of meaning face problems at least as serious as those he identifies in the strong programme's finitism. This is not to say that the strong programme is problem-free: it fails to give sufficient acknowledgement to non-conventional constraints on meaning formation and change. It is also suggested that, as they are currently conceived, realism's intensionalism and the strong programme's extensionalism are irreconcilably incompatible at such a basic level that the 'debate' between them reduces to an exchange of 'assurances'.
\end{abstract}

Keywords: strong programme, sociology of scientific knowledge (SSK), meaning finitism, extensionalism, intensionalism, transcendental realism

JEL Classification: B40, Z13

In a previous issue of this journal, David Tyfield (2008) offered a twopronged critique of the 'strong programme' in the sociology of scientific knowledge (hereafter SP). ${ }^{1}$ The first prong is the well-known claim that the SP is logically flawed because it entails a self-refuting relativism. ${ }^{2}$

\footnotetext{
1 This article restricts itself to the Edinburgh School's 'strong programme' in the sociology of scientific knowledge, as this is the focus of Tyfield's (2008) critique. David Bloor's work, and especially his Knowledge and social imagery (1976), is taken to be exemplary of this School's approach and doctrine. The Paris and Bath Schools in the sociology of scientific knowledge are exempted from this analysis.

${ }^{2}$ Yann Giraud and E. Roy Weintraub's (2009) reply to Tyfield (2008) focuses upon this criticism. Their counter-argument, in summary, is this: Tyfield presupposes a conception of truth that prejudices his conclusion and is not accepted by advocates of the SP. In essence, if proposition P is judged to be true by standard S (presupposing, say, a pragmatist theory of truth as Giraud and Weintraub say the strong programme
} 
The second prong is an attack on the SP's finitism and extensionalism. Tyfield argues that the SP's finitism entails a false dichotomy, that it results in incoherence, and that it neglects a superior alternative account of meaning, namely intensionalism. In the present article, the relationship between finitism and the SP will be outlined, and then Tyfield's critique and his proposed alternative will be examined and shown to be problematic. It is then argued that the flaws in the SP are not due to its lack of an intensionalist theory of meaning. Finally, it is suggested that the realist-SP debate over meaning reflects the much older essentialist-nominalist dispute.

\section{THE STRONG PROGRAMME'S CONVENTIONALISM AND FINITISM}

The SP has been characterised by Bloor $(1976,4-5)$ as possessing the following defining features. (1) It is concerned with discovering the causes of scientific beliefs and knowledge-claims, and especially (but not only) the causal social conditions that contribute to their coming about. (2) It seeks to explain the content of scientific claims irrespective of whether they are taken to be true or false, rational or irrational, successful or unsuccessful. That is, it does not seek to explain only false, irrational, or unsuccessful claims as does the 'traditional' Mertonian (1973) sociology of scientific knowledge. (3) The same types of causes attributed to true, rational, and successful scientific claims are to be attributed to false, irrational, and unsuccessful ones. This amounts to combining (1) and (2), viz., that the same kinds of causal explanations, especially involving social factors and communal interests, should be attributed to both true and false claims. (4) SP is itself a scientific enterprise, and thus it can be investigated on the basis of (1), (2), and (3). The mode of explanation that the SP uses to account for scientific claims should be applicable to the SP itself.

We might reasonably summarise the above key features in the following way: the SP is concerned with discovering the conditions, and especially the social forces and group interests, which causally explain all scientific beliefs or knowledge-claims (including those made by the SP itself), be they true or false, rational or irrational, successful or unsuccessful.

does) and false by an incompatible standard $S^{*}$ (presupposing, say, a realist correspondence theory of truth as they say Tyfield does), it is illegitimate for Tyfield to say that $\mathrm{P}$ is 'in fact' false just because he assumes $\mathrm{S}^{*}$ to be correct. In what follows, insofar as it is possible, I seek to avoid the 'relativism and self-reflectivity debate' in which Giraud/Weintraub and Tyfield (2009) engage. 
The SP has gained a reputation for being radical and innovative, because it presents itself as breaking with what it takes to be the foundationalism of traditional epistemology, which is said to hold that knowledge consists in the guaranteed justification of true beliefs (or propositions). Bloor rejects the view that we can justifiably judge whether statements about the (mind-independent) world are true, where, as per the traditional correspondence theory of truth, 'true' stands for a strict one-to-one matching-relation between the terms of a proposition and the elements of some 'real object' which it is held to identify and represent: "At no stage is this correspondence [between a theory and reality] ever perceived, known or, consequently, put to any use" (Bloor 1976, 34). ${ }^{3}$ Bloor's rejection of the correspondence theory is made on two grounds. First, the concept of correspondence is "very vague" and "difficult to characterise in an illuminating way" (Bloor 1976, 32). Second, it is not possible to know whether the correspondence relation holds because "[w]e never have the independent access to reality that would be necessary if it were to be matched up against our theories" (Bloor 1976, 34). ${ }^{4}$

Bloor invites controversy with his alternative conventionalist epistemology. He argues that:

[T] here is one sort of correspondence that we do indeed use. This is not the correspondence of the theory with reality but the correspondence of the theory with itself. Experience as interpreted by the theory is monitored for such internal consistency as is felt important (Bloor 1976, 33).

Scientific theoretical and empirical developments are regulated by similarly "internal principles of assessment" such as predictive success and accuracy, scope and coherence; and the trajectory of development is determined and motivated by "our theories, purposes, interests, problems and standards" (Bloor 1976, 34).

Since scientific claims are developed and assessed by the internal, self-imposed "standards" or methodological "requirements" of our theories and experience-rather than by correspondence with realityand since historical analysis is said to reveal that there are numerous

\footnotetext{
${ }^{3}$ Bloor says this in the context of commenting on Priestley's experimental testing of the theory of phlogiston.

${ }^{4}$ Bloor supports his claim by noting that as theories have failed on their own terms and have been subsequently revised, apparently known truths have been rejected and revised over time.
} 
such standards and requirements, then "[i]t should be possible to see theories entirely as conventional instruments for coping with and adapting our environment" (Bloor 1976, 35). ${ }^{5}$

How does all this relate to finitism? According to Bloor (1983), finitism "is probably the most important single idea in the sociological vision of knowledge. It shows the social character of that most basic of all cognitive processes: the move from one instance of concept application to the next" (Bloor 1991, 165). ${ }^{6}$ So, the SP's sociological theory of knowledge, including scientific knowledge, is built upon a sociological theory of meaning.

Finitism presupposes an extensionalist theory of meaning. And extensionalism holds that universal terms are used in context-specific ways to denote classes of particulars. In its modern formulationfollowing Wittgenstein-it is 'use that determines meaning', not the other way around; and it is rules about the use of particular and universal terms in a variety of context-specific 'language games', learned in an iterative (and initially ostensive) fashion, that give those terms their specific meanings. Importantly, however, the past application of a given word to finite cases does not determine how that word will be used in future cases (hence the term 'finitism'). There is no logically necessary reason why the rules of use in themselves would prevent any kind of new extension, be it to new particulars of an existing class, or to entirely new uses for entirely different classes. ${ }^{7}$ Although the formation and extension of terms to new particulars have no logical constraints, there must be some kind of constraint on existing and new extensions lest conceptual chaos ensue.

According to Bloor (2007), Wittgenstein held that narrowly 'philosophical' attempts to constrain meanings with formal and abstract conditions must founder on the rocks of an infinite regress: "if a rule

\footnotetext{
${ }^{5}$ Despite this, Bloor argues that the notion of-or better, the term-'truth' still has some use-value and so should not be discarded. It serves a "discriminatory function" used to indicate which theories are currently assessed to 'work' and which do not; a "rhetorical function" by which a claim is authoritatively recommended as more than "mere belief"; and a "materialist function" by which "we mean just this: how the world stands" (Bloor 1976, 35-36). Obviously, these functions have no truck with the correspondence notion of truth.

${ }^{6}$ Bloor claims that finitism can be traced back to Ludwig Wittgenstein's (1973 [1953]) Philosophical investigations.

7 Take, for example, the term 'unemployed'. In the former case (extension to new particulars of an existing class) one may extend the term to cover, say, those who have lost hope in finding work and have thus taken early retirement ('hidden unemployed'). Yet one may use the term in an entirely different way to denote an entirely new classsay, to cynically denote legislatively powerless Heads of State.
} 
depends on an interpretation then the interpretation demands an interpretation" and so on. Instead, the limits-the particular (and changeable) rules of meaning-formation and meaning-extension-are determined by a whole way of life. In Bloor's words, for Wittgenstein:

[T] he real determinants of the next application, and the real sources of the discrimination between correct and incorrect steps and applications, were not to be found in the realm of formal specifications and justifications but amongst the totality of contingencies that impinge on the episode. He was not saying that the move to the next case was undetermined. Rather, the determinants lie around or behind the formal specifications but do not appear in or amongst them (Bloor 2007, 212).

Needless to say, for Bloor, the "totality of contingencies" includes enforced, contested and "negotiated" conventions that are in large part caused by social, institutional forces, and the particular "needs" and "interests" of a community. Thus, the linguistic chaos that finitism (understood abstractly) threatens is prevented by the normativity inherent in communal agreement over conventional rules of "right" word-use. ${ }^{8}$ And so it is with the communal activity of science. One can thus sensibly characterise theories, methods, and facts as being 'inherently social' and 'socially constructed', since the extensional semantic properties and the formal structures of scientific theories as well as their empirical findings are-and for Bloor must be-limited and determined by normative social conventions.

This account of normative, conventional, socially influenced scientific knowledge is said to draw its force, on the one hand, from numerous empirical case-studies of meaning-formation and change in science, and on the other hand from the inadequacy of the dominant alternative account of meaning. ${ }^{9}$ The dominant alternative, in very

\footnotetext{
${ }^{8}$ Apropos of this point, Bloor says:

The group collectively 'decide' on the norms of proper usage of their concepts and classifications and they create the norms of their correct use in the course of invoking them. They do not collectively discover the norms, as if they were a further feature of the world, even if it may occasionally seem like this to the individual concept user (Bloor 2007, 215).

${ }^{9}$ The present article avoids an analysis of any case-studies for two related reasons: First, there are now very many and varied case-studies in the literature. Any case-study analysis then would have to be highly selective, and in so doing, would inescapably open itself up to the charge of 'cherry picking'. Second, some realist critics of the SP and other modern schools of the sociology and ethnography of science dispute the veracity of all such case-studies. For example, Peter Slezak argues as follows:
} 
general terms, is intensionalism. This position holds that the uses of words are determined by their meanings, where meanings are due to the common or essential properties of entities either ante rem in the realm of ideas (à la Platonism) or in re in the realm of the material (à la Aristotelianism). The SP's conventionalism undermines intensionalism because, with different "internal principles of assessment" motivated by different "theories, purposes, interests, problems and standards", there is logical space for different so-called 'essential' properties at different historical junctures or in contemporaneous conflict. By the SP's lights, this is a reductio of intensionalism.

\section{A REALIST CRITIQUE OF FINITISM}

Tyfield (2008; and 2009) draws upon a robust ontological realism to attack the SP's account of meaning. He asserts that the SP sets up a dilemma that forces us to choose between either logically predetermined particular future uses of terms or logically undetermined particular future uses $(2008,76)$. In presupposing extensionalism we are then seemingly compelled to choose the latter option-since logically and universally pre-set usages are taken to be manifestly false-and thus to commit ourselves to a logically indeterminate 'negotiation' of rules over extensions that are causally influenced by social forces.

For Tyfield, this dilemma is illusory because (i) finitism entails the fatal problem of making the SP 'unintelligible' thereby rendering it an

The extensive body of case studies repeatedly invoked by sociologists to answer their critics has been taken to establish the thesis that the contents of scientific theories and beliefs have social causes, in contradistinction to psychological ones. [...] [T] he claims of social determination of beliefs are all the more extraordinary in view of the utter failure of these case studies to support them. Critics have challenged precisely the bearing of these studies on the causal claims, and so repeatedly citing the burgeoning literature is to entirely miss the point. [...] [T]o the extent that social factors are indeed ubiquitous, establishing a causal connection requires more than merely characterizing in detail the social milieu which must have existed. These more stringent demands have not been met anywhere in the voluminous case studies in the SSK literature. [...] Thus, it is a truism to assert, as Shapin does, merely that "Culture [taken to include science] is developed and evaluated in particular historical situations". Shapin undertakes to refute the accusations of empirical sterility by a lengthy recounting of the "considerable empirical achievements" of the sociology of scientific knowledge. But he is simply begging the question with his advice that "one can either debate the possibility of the sociology of scientific knowledge or one can do it" (Slezak 2000, 7-8).

This indicates that the status of case-studies, and what they demonstrate or not, is the subject of a debate all of its own. To merely gloss over this debate would be to do an injustice to all sides, and to engage with it would consume an entire article. The prudent path taken here is to leave the matter to another time and place. 
unacceptable option in the first place, and (ii) intensionalism is not given its due consideration as a viable account of meaning. Let me stress three aspects of Tyfield's position:

(A) With respect to (i), Tyfield argues that the SP is shown to be unintelligible once it is realised that the 'social forces' governing rules of term-use are themselves said to be rule-governed. Since finitism's rules do not analytically tell us about future states of affairs, social forces themselves are analytically indeterminate and so the grounds for stable term-use, and thus stable meanings, are undermined. If rules really did have no logically determinate implications (that is, if finitism were true), then current rules allow one to say (mean) anything at all and nothing in particular about the future-even the immediate future. Thus, the rules governing statements in the SP (and everywhere else) mean anything at all and nothing in particular. If statements can mean anything at all and nothing in particular, then statements are unintelligible. Therefore, if finitism, and so the SP, is true, the SP is unintelligible.

(B) In order to establish (ii), Tyfield argues that because rules-both theoretic (relating proximately to meaning) and extra-theoretic (relating proximately to behaviour)-do indeed exist, do play a causal role in the determination of meanings, and are intelligible to us, they must "not, at any given time, [be] totally unlimited in application", and so "do have intrinsic, determinate content, i.e., they are intensional and not just extensional" (Tyfield 2008, 78), where "intensionality is understood here as the possibility of a proposition or term to have a determinate meaning in a given sociohistorical context and not a fixed, complete and perfect essence" (Tyfield 2009, 65).

In particular, Tyfield asks that a crucial distinction be acknowledged: words have determinate current content but this does not uniquely determine future content for all-time. Accepting this implies "internal relations of necessity between different meanings, hence rendering meaning relatively resistant to our use of it so that we cannot simply do as we please-even collectively-with meaning, pace [SP]" (2008, 80; emphasis in the original). For example, in our society at the present time, there is a necessary semantic relation between the terms 'water' and 'H2O'. We cannot simply choose to mean, say, 'electricity' when we speak of water. For we know that there is something about an entity being water-i.e., its molecular structure-over and above the application of some other terms that gives the word its meaning. That said, naming-rules at a particular time in a particular community do not 
universally determine meaning for at least two reasons. First, intensions depend on knowledge: it is possible, say, in a community unaware of molecules, that 'water' just means 'liquid that falls from the sky'. Note that this latter case is still intensional because it is crucially about something being water. Second, the same words can be extended to quite new cases with new meanings-for example, 'watery eyes', 'watery grave', 'an explosion at the Water Works'. Nonetheless, these extensions are ultimately parasitic upon the original 'essential' or 'basic' intensional meanings which lie at the base of the commonality between all conceivable uses of the term 'water'. Again, without this kind of anchor, linguistic chaos would ensue.

In his rival account of meaning, Tyfield implicitly draws upon Roy Bhaskar's transcendental realism, ${ }^{10}$ so for a more complete exposition let us turn to the latter's quite explicit statements on the matter. In the course of his discussion of what science seeks to discover, Bhaskar (1975) argues that "Leibnizian" natural kinds (kind K is composed of all x's with the "constitution or intrinsic structure" N) are expressed by "real definitions". In Bhaskar's own words:

Real definitions are definitions of things, substances and concepts; nominal definitions are definitions of words. (Nominal essences are the properties that serve to identify things). Real definitions, in science, are fallible attempts to capture in words the real essences of things which have already been identified (and are known under their nominal essence) at any one stratum of reality. As so conceived, they may be true or false (not just or even more or less useful). [...] [For example] [i]f the real essence of copper consists in its atomic (or electronic) structure, its nominal essence might consist in its being a red sonorous metal, malleable and a good conductor of electricity, etc. But conversely just because the word 'copper' in science has a history, and at any moment of time a use, the nominal essence of copper cannot suddenly be designated by the use of 'reppoc' or 'tin'. Nominal definitions in science cannot therefore be

\footnotetext{
${ }^{10}$ Although Tyfield never explicitly says so, it seems clear that he is drawing heavily upon Roy Bhaskar's (1975; 1979; and 1989) transcendental realism (now called 'critical realism'). This variant of realism has been most conspicuously championed in economic methodology by Tony Lawson (1997; and 2003). My supposition is based on Tyfield's appeal to a "novel approach [that] is effectively 'transcendental' or 'critical' in nature, involving examination of the necessary conditions of possibility of the premise", and "an alternative approach of a critical and transcendental philosophy" (Tyfield 2008, 63), which deploys "transcendental, i.e., a specifically philosophical, argument", a "transcendental approach", "transcendental reasoning" (Tyfield 2008, 80, 81) and a "transcendental analysis" (Tyfield 2009, 60, 61, 68).
} 
conceived as stipulative, arbitrary or matters of convention (Bhaskar 1975, 211).

Despite the falliblist caveat, we can say that once the real essences of things have been discovered and correctly expressed in real definitions, those definitions must universally and invariably determine the correct classification of things and regulate their "nominal definitions" - that is, they would regulate the correct use of words by reference to the "constitution of things". This is an intensional approach to meaning par excellence, and for transcendental realism goes to the heart of scientific activity:

Scientists attempt to discover what kinds of things there are, as well as how the things there are behave; to capture the real essences of things in real definitions and to describe the ways they act in statements of causal laws. [...] Thus there is no conflict between explanatory and taxonomic knowledge. Rather, at the limit, they meet in the notion of the real essences of the natural kinds, whose tendencies are described in statements of causal laws (Bhaskar 1975, 173-174).

With this additional information, Tyfield's crucial distinction between determinate meaning and uniquely determining meaning progressively disappears as science achieves its goal of discovering real essences expressed by (correct) real definitions. "At the limit", on this view, there would seem to be no means by which meanings could change (other than by, say, disturbing psychological or social forces); that is, contra Tyfield's claim, determinate meanings would indeed uniquely determine scientifically established rational future uses.

(C) Tyfield $(2008,80,81)$ attributes his identification of the SP's fatal flaw of extensionalism and the necessity of an intensional theory to the use of "transcendental, i.e., a specifically philosophical, argument" or "transcendental reasoning" in accordance with transcendental realism. A transcendental realist argument, as originally formulated by Bhaskar (1975), begins with the question: 'What is necessary in order for P to be possible?' In other formulations, it begins with the question: "What is necessary in order for $\mathrm{P}$ to be intelligible?" The argument seeks to demonstratively infer and establish a priori what must be true from the possibility (or intelligibility) of $\mathrm{P}$, where $\mathrm{P}$ has already been fallibly established a posteriori. In short, it seeks to establish synthetic a priori 
truths. A transcendental argument can be expressed in a number of ways. One form is the following:
(1) $\sim \square \mathrm{Q} \rightarrow \sim \diamond \mathrm{P}$
(2) $\diamond \mathrm{P}$
(3) $\therefore \square \mathrm{Q}$

We can summarise Tyfield's 'negative' and 'positive' transcendental arguments as follows:

(1) If SP is true, then extensionalism is true.

(2) If extensionalism is true, then determinate meanings are impossible.

(3) If determinate meanings are impossible, then SP is unintelligible.

(4) $\therefore$ If SP is true, then SP is unintelligible. [From (1), (2), (3)]

(5) Determinate meanings are possible.

(6) $\therefore$ Extensionalism is false. [From (2), (5)]

(7) If extensionalism is false, then intensionalism is true.

(8) $\therefore$ Intensionalism is true. [From (6), (7)]

\section{CRITICAL COMMENTS ON THE REALIST CRITIQUE OF FINITISM}

I would make three related critical comments on Tyfield's critique of finitism. The first comment is really just a rectification of a conceptual confusion. The remaining two however, are more substantial in that they suggest that Tyfield's approach has difficulties that are not dissimilar to the ones he himself raised with finitism.

Regarding (A), Tyfield asserts, slightly strangely, that the SP's "positive claims, if true, would be unintelligible" $(2008,77)$. I say this is strange because if one takes "unintelligible" here to refer to a contradictory statement, ${ }^{11}$ and accept the axiom of classical logic that a contradictory statement must be false, then it is impossible for such a statement to be unintelligible and true. Thus, ironically, the claim: 'If the SP is true, then the SP is unintelligible' is itself unintelligible. Further, this being so, Tyfield's contrapositive, "[i]t follows that if we understand

\footnotetext{
${ }^{11}$ We might consider three possible types of unintelligibility. Logical unintelligibility: where a statement contains a logical contradiction such as 'The sky is blue and the sky is not blue'. Linguistic unintelligibility: where a statement does not follow (or fails to approximately follow) any grammatical rules, such as 'Is was pile out', or its terms are highly ambiguous, such as in the metaphorical lines, 'The night shifts her gaze, spawning a thousand doubting tears'. And translation unintelligibility: where a statement is expressed in a language or a code that one does not have sufficient knowledge to decipher. (Thanks are due to Dr. William E. Worner for useful discussions on this matter.) It is assumed here that Tyfield is using the term in the first sense, because the others do not serve Tyfield's argument.
} 
the claims [of the SP], they must be wrong", does not logically follow. The premise that is missing from Tyfield's argument that would solve this problem is: 'If alleged rules do not have determinate implications, then they are not really rules at all'. The implicit presupposition that 'there are rules that are not rules' must be false. The correct formulation would then be, 'If the SP contains contradictory propositions, then taken as a whole, the SP is both unintelligible and false'.

Regarding (B), as noted, the distinction between determinate meaning and uniquely determining meaning progressively disappears as science achieves its goal of discovering real essences expressed by (correct) real definitions. But this would seem to imply that until that "limit" is reached-until the Holy Grail of real essences has been discovered-we do not really have meanings that are so ontologically 'tied down'. What then determines meanings, for it cannot be as yet unknown real essences? Perhaps we could appeal to "Lockean" nominal definitions-that is, classifications defined by knowledge of the 'surface' properties of things. But is it not the case that things possess very many, maybe even an infinite number of properties? How are we to select the limited 'defining' properties without the guidance of the real essences? Bhaskar tells us that:

To classify a thing in a particular way in science is to commit oneself to a certain line of inquiry. Ex ante there will be as many possible lines of inquiry as manifest properties of a thing, but not all will be equally promising (Bhaskar 1975, 210).

True enough, but does that not mean that the classification of things-and the meanings of terms-will be governed not by real essences or even by properties of things per se, but by the somewhat nebulous state of "commitment" (surely something influenced by social conventions) as well as methodological conventions that give meaning to terms such as "promising"? Alas, this would seem to return us to an extensionalist notion of meaning formation, to say nothing of the SPthe rejection of which is the raison d'être for the realist-intensionalist theory. One way out of this might be to say that we do have knowledge of at least some real essences and thus do have some real definitions. ${ }^{12}$ But how do we know this to be the case? The real essence of a thing is said to be "the most important explanatory property", but how do

\footnotetext{
${ }^{12}$ Bhaskar seems confident about hydrogen, nickel, and copper at least (Bhaskar 1975, $173,210,211)$.
} 
we determine the meaning of the somewhat vague phrase "most important"? Most important for what explanatory purpose? Whose purpose? And all this is to say nothing of what we shall decide "explanatory" means. At some point, it would seem, we must simply assert that this or that is the ultimate real essence and real definition of $\mathrm{x}$ and leave it at that. This involves making an assumption at some point that a final truth has been achieved, and about the impossibility of the future discovery of error or improvement. That would return us to a basic analytical arbitrariness-and even to the relativism that the entire effort was designed to avoid in the first place.

Regarding (C), the central challenge for transcendental deductions, as with all deductions, is for the premises to be formulated and specified quite precisely (and in Bhaskar's case, they must also be empirically well-secured). Any ambiguity in or doubts about the truth of the premises allows for the logical possibility of an infinite number of alternative conclusions to be deduced (or none at all, depending on one's interpretation of what is an allowable deductive inference under such conditions). The problem here is that Bloor's account of meaning finitism allows for the possibility of ambiguity in, or doubts about, propositions. Yes, the normativity of social conventions does foreclose chaotic word-use (at least according to Bloor, but not to Tyfield), but it does not eliminate indeterminism in word-use because "negotiation" over and innovation in conventions are always possibilities in living communities, including scientific and philosophical communities. As such, there are always grounds for ambiguity and doubt which undermines the prerequisites of an epistemically secure transcendental deduction. So, if we are to seriously claim that SP can be definitely refuted by means of a transcendental deduction, we must presuppose the falsity of Bloor's meaning-finitism and the truth of an undiluted intensionalism. In other words, in order to even mount Tyfield's transcendental argument, we must presuppose what is intended to be proved (petitio principii).

\section{THINKING ABOUT THE STRONG PROGRAMME ONCE MORE}

Bloor is concerned to assuage worries about arbitrariness often attributed to conventionalism. He explicitly argues that:

[C]onventions are not arbitrary. Not anything can be made a convention, and arbitrary decisions play little role in social life. The constraints on what may become a convention, or a norm, or an 
institution, are social credibility and practical utility. Theories must work to the degree of accuracy and within the scope conventionally expected of them. These conventions are neither self-evident, universal or static. Further, scientific theories and procedures must be consonant with other conventions and purposes prevalent in a social group. They face a 'political' problem of acceptance like any other policy recommendation (Bloor 1976, 37-38).

In another place, he re-affirms the point:

Conventionality [...] implies that the behaviour of any one follower of the convention is conditional on the continued conformity of a sufficient number of others. The collective 'decision' to use a concept in a certain way is not arbitrary; it must be one that is perceived to have utility for the group of users and it must be consistent with, and sustainable by, their innate cognitive proclivities-such as the natural operation of their pattern-matching machinery (Bloor 2007, 215).

These passages certainly serve to rule out 'actually existing arbitrariness' (as opposed to 'in principle logical arbitrariness'). What could be objected to, however, is what it ignores. In particular, I suggest that Bloor's account of the constraints on the formation of knowledgeclaims, and meanings more generally, does not take sufficient account of objective constraints other than those of negotiable social conventions. That is to say, given a set of discursive conventions, there are still some objective intra-theoretical, inter-theoretical, and 'worldly' constraints on extensional possibilities.

This claim can be initially illustrated by means of maximally conventional cases of both objects and activities. For example, take Bloor's $(1991,174)$ "valid banknote" example as the utmost case of the conventionality of an object. Even here, there are constraints that are not really due to social conventions, such as practical considerations about size, durability, reproducibility, and so on, of the things which are to function as notes. Further, these practical considerations can change depending on yet other objective (non-conventional) factors-for example, technological change ('electronic' money) rendering constraints on physical durability largely irrelevant. An example of an activity that is maximally conventional is the game of chess. The rules of chess are largely conventional (the initial position of the kings on the chess board is not somehow inherent 'in nature' or somehow otherwise 'in' the intensional sense of 'king'). A change in initial position on the board 
may be negotiated between players-or forced by one player upon the other. There are limits however, as to what could be negotiated/forced in order for there still to be a contest (a game) between players. For example, it would not be possible to retain all the existing rules, but negotiate the kings' initial positions to be adjacent to the opposing queens, or that the kings be initially positioned in a cupboard. And of course, there must be some real object that can be practically used as (conventional) representations of chess pieces (be it bits of wood, or pixels on a screen, or whatever). Mutatis mutandis less-than-maximal cases of social conventionality.

Let us then look very briefly at objective intra-theoretical, intertheoretical, and 'worldly' constraints in turn. With respect to nonconventional intra-theoretic constraints, one can find them in logic, mathematics and empirics. For example, in the case of logic, there is an intra-theoretical non-conventional constraint of general coherence: non-contradiction within some set of inferential rules is an objective constraint on particular inferences, such that it is not possible to incorporate, say, ' $\mathrm{P}$ is $\sim \mathrm{P}$ ' or ' $\mathrm{P} \rightarrow \sim \mathrm{P}$ ' or ' $\sim \mathrm{P} \& \square \mathrm{P}$ ' as axioms. ${ }^{13}$

\footnotetext{
${ }^{13}$ It may be noted that Bloor does not deny that there are constraints per se on what is negotiable in logic or mathematics. For example, with respect to modus ponens, although characterising it as a "logical convention", Bloor offers two types of constraints that prevent the convention from being abandoned. The first constraint upon dropping modus ponens is a biological one: it is "innate", a "feature of our natural rationality". The second, and apparently only other constraint, however, is a social one: modus ponens is prescribed a "cognitive institution" which is given "special protection" from any possible doubts that might otherwise arise due to some ingenious counter-example or other.

We may grant that modus ponens is 'hard-wired', and even grant that it is given institutionalised "special protection" from nocturnal doubts. But we may still wonder why such protection is necessary. Might it not be because without modus ponens, most of our other reasoning just could not 'go through'? That is, is not the "special protection" really just the making explicit of what is an implicit intra-theoretic constraint?

As an example of the kind of constraints on mathematics Bloor has in mind, one may look to his discussion of Lakatos's historical analysis of the polyhedron. Bloor writes:

The concept of a polyhedron could not govern men's behaviour in deciding what was to be included in, and what was to be excluded from, its scope. This does not mean that nothing acts as a constraint in these circumstances. The extension and elaboration of concepts can plausibly be seen as both structured and determined. They are determined by the forces at work in the situation of choice-forces which may be systematically different for different men (Bloor 1976, 139).
}

However, he does not nominate theoretically objective constraints as the "forces at work in the situation of choice". Again, he appeals to social constraints explained by factors such as "the professional commitments and backgrounds of actors" (Bloor, 1976, 140). He seeks to illustrate his claim by an analogy with the power-relations between a parent and a child. When the child extends the word 'hat' to a tea-pot lid: 
This is precisely why counter-examples to inferential rules are objects of such consternation to logicians (see Smith 1984; and Mortensen 1989). The same goes for mathematics, as it also does for empirical investigations generally. For example, given the conventional stipulation of a concept in terms of discrete variables, it is not then possible to subject it to differentiation (except by fitting some continuous curve and differentiating that). Or, given that the conventional meanings of 'height' and 'weight' have been stipulated, the measurement of height cannot be used as a measure of weight. Or, once it has been stipulated that demand for a commodity is strictly 'price elastic' only where the coefficient $\eta \leq-1$, it is not then possible to say that demand is 'fairly price elastic' where $\eta=-0.2$.

There are also non-conventional inter-theoretical constraints. For example, it is not possible to apply the rules of propositional logic to a poem by Dylan Thomas because the latter's terms are not sufficiently clear to be made subject to analysis by the former. Or, given our current state of knowledge, we are constrained in subjecting the amorphous concept of 'consciousness' to psychometric analysis of the kind used by 'differential' theories in psychology. Or, there is an objective constraint on the translation of an exploitative relation given in terms of Robinsonian monopsony theory into an exploitative relation given in terms of a Marxian labour theory of value.

There can also be mundane practical constraints: conducting a molecular analysis of every beam of steel used in the construction of a building is not feasible due to time and financial constraints. Similarly, a psychological analysis of each entrepreneur in a national industry in order to represent the thought processes going into the determination of market prices faces objective time and financial constraints. Conducting an experimental analysis of the behaviour of the particles at the centre of the Sun is not physically feasible due to the extreme temperatures and the fragility of available equipment. Observational investigation of the existence of life on the other 'side' of the universe is

Parental authority will soon cut across the child's natural extension of the concept and insist that really the object is not a hat but a lid. A socially sustained boundary is drawn across the flow of the psychological tendency. [...] It should be possible to transfer this perspective to the data in Lakatos's example (Bloor 1976, 139). 
not feasible due to the extreme distance and the limited lifetimes of human beings. ${ }^{14}$

Finally, there is the seemingly most philosophically contentious case of worldly constraints. Here we need not refer to 'the world in-itself' and thereby fall into basic problems associated with foundationalist epistemology. ${ }^{15}$ We may instead refer to 'the world-under-description', where for us, what is observed and posited to exist must come under a human-made description of some kind (either explicitly theoretical or composed of 'everyday' concepts). The descriptions are conventional, historically contingent, and can change in part because of social forces, but also, given a set of stipulated descriptions, there are objective limits on what can be said about the 'real objects' which are distinct from those descriptions. For example, given a definition of unemployment and a means of measuring unemployment so described, it is not possible for measured unemployment to increase unless there is a change in the world (the real object) under that description.

Further, how might descriptive inadequacy or failure be construed? Take a posited unobserved theoretical entity such as, say, natural unemployment. Again, this expresses something about the world-underthis-description, but given the (conventional) 'theoretical' description and given what it implies under some set of conditions, if under the relevant descriptions it fails to predict what it claims to be able to, we

\footnotetext{
${ }^{14}$ It is noted that Bloor alludes to the requirement that a convention must have "practical utility" and be "perceived to have utility for the group of users" (Bloor 1976, 37-38; 2007, 215). Might this not cover what is being pointed out in the above examples? The problem here is that it is by no means clear that this requirement of Bloor's is supposed to be understood as independent of other social conventionsafter all, such utility is characterised as "perceived" by "the group". Such 'perception' seems best glossed as 'interpreted' or 'regarded' rather than, say, 'directly observed', and by the lights of the SP, interpretations are themselves the function of pre-existing social conventions (rather than being individually subjective). In short, what is to count as 'being useful' and even what 'useful' means is itself subject to negotiable "decisions" by a community. This being so, it is suggested that Bloor's references to "practical utility" are not of the objective sort discussed above.

${ }^{15}$ The most basic problem was first articulated by the Sceptics in antiquity and has haunted (and motivated) epistemology ever since. Following Suchting (1986), the problem can be presented as follows. Take the necessary and sufficient conditions of 'knowledge' to be justified true belief. In order to establish a guaranteed relation of correspondence between a knowing subject and a known object, we require a criterion of justification. In order to ensure that this criterion is indeed correct-that it does the job of providing warrant-it too must be justified. Now, this leads us either to an infinite regress (that is, an unending list of different justificatory criteria), to circularity (that is, the original criterion is said to be justified by itself), or to dogmatism (that is, a criterion is ultimately merely stipulated as an intuitively self-evident foundation). None of these options satisfy the conditions of the original conception of knowledge. Thus, there is no knowledge so defined.
} 
may be inclined to regard this as an inadequate description for our purposes and may be thereby motivated to develop or choose a new one. In these cases, the constraints are 'worldly' ones, despite being inextricably bound up with a conventional theoretical description. Indeed, it is because we seek to operate with a 'world-under-description' that the worldly constraint is an objective constraint. ${ }^{16}$

\section{THE NOMINALIST-ESSENTIALIST COUPLE}

By focusing on the SP's finitism and by offering an alternative approach to meaning, Tyfield implicitly invokes an ancient debate, namely that between essentialism and nominalism.

Briefly, the nominalist approach holds that universals amount to nothing more than words used to group things. Particular entities can be grouped together into sets/classes ultimately by the sheer application of a word to particular individuals. The cause of the grouping-together is a secondary, but not unimportant, matter-it could be perceived or imagined resemblances, habits of the mind, social conventions of a community, religious decree, or whatever. For the nominalism

\footnotetext{
${ }^{16}$ It is noted that Bloor seeks to tone down concerns that the SP entails some kind of idealism-that is, SP does not deny the existence of the material world and so acknowledges objective worldly constraints. He states:

No consistent sociology could ever present knowledge as a fantasy unconnected with men's experiences of the material world around him [...]. The whole edifice of sociology presumes that men can systematically respond to the world through their experience, that is, through their causal interaction with it. Materialism and the reliability of sense experience are thus presupposed by the sociology of knowledge and no retreat from these assumptions is permissible (Bloor 1976, 29).
}

Yet when it comes to saying what materialism amounts to, how it is 'cashed out' by the SP, we find it reduces to an assumption, a schema, an abstract idea, a presupposition:

All our thinking instinctively assumes that we exist within a common external environment that has a determinate structure. [...] Opinions vary about its responsiveness to our thoughts and actions, but in practice the existence of an external world-order is never doubted. It is assumed to be the cause of our experience, and the common reference of our discourse. [...] [It is the] ultimate schema with which we think. [...] [W] hat is needed to make sense of affirmation [of some truth-claim] is the instinctive but purely abstract idea that the world stands somehow or other, that there are states of affairs which can be talked about. This is what is provided by the schema of ideas that I have called the materialist presupposition of our thinking (Bloor 1976, 36, emphasis added).

Historically, such an account of what 'the material world' amounts to is identified with idealism-either subjectively (e.g., Berkeley) or in some sense objectively (e.g., Kant or Hegel). Indeed, Michael Devitt (1997, chapter 13) argues (negatively) that social constructivism draws upon an idealist Kantian heritage, while Steven Vogel (1996) argues (positively) for a Hegelian-inspired social constructivism. 
associated with the SP, a socially caused rule R over term $\mathrm{T}$ determines the (conventional) use of $\mathrm{T}$ for some $\mathrm{x}$ 's, which in turn determines the (conventional) meaning of $\mathrm{T}$ over those $\mathrm{x}$ 's. By extension, $\mathrm{x}_{\mathrm{i}}$ is $\mathrm{T}$ (meaning) due to R over $\mathrm{T}$ (use) for a set that includes $\mathrm{x}_{\mathrm{i}}$. The emergence of new R's, especially by a change in social forces, generates new meanings.

I suggest that the underlying concern about the nominalist approach is that because definition and classification are, logically speaking, ultimately arbitrary, this would seem to render critical interrogation of rival concepts overly contingent and fragile, opening up the possibility of a Thrasymachean 'might is right' world of meaning-formation and change. If the nominalist were to argue that there can be conventional principles of critical judgement (see Bloor 1976, 38), the reply back can be that: this is ultimately arbitrary too, and would hardly engender great confidence if it were the powers-that-be who were to impose their definitions of what counts as 'legitimate criticism'. It is this kind of concern, I speculate, that underlies the motivation for an independent and impartial way of forming concepts that leads to the advocacy of essentialism.

The essentialist approach to definition and classification holds that universals are properties of entities and that a class (kind) of entities is intensionally defined as all those entities that possess a certain essential property or set of properties (either ante rem or in re). The meaning of a term is determinate because the essential properties of things, and so classes/kinds, are determinate. So, the meaning of a particular namingword is given by the class into which a named thing falls, and the class into which it falls is determined by the thing's essential properties. For the essentialism associated with transcendental realism, the structural properties $\mathrm{P}$ of all $\mathrm{x}$ 's determine the (real) meaning of $\mathrm{T}$, which in turn determines the (correct) use of T over all x's. By intension, $\mathrm{x}_{\mathrm{i}}$ is $\mathrm{T}$ (use) due to $\mathrm{x}_{\mathrm{i}}$ possessing $\mathrm{P}$ (meaning). The discovery of new P's generate new meanings.

Ironically, the essentialist approach carries with it a problem similar to the one identified with nominalism. It can be brought out by the following question: if there are two or more competing essentialist definitions, how are we to decide which is the 'true' one? Which one should we use? Suppose we have a thing, $x$, that has structural properties $\mathrm{P}_{1}, \mathrm{P}_{2}, \ldots, \mathrm{P}_{\mathrm{n}}$. $\mathrm{P}_{1}$ of $\mathrm{x}$, under the right conditions, manifests event $\mathrm{E}_{1} ; \mathrm{P}_{2}$, under the right conditions, manifests $\mathrm{E}_{2}$; and $\mathrm{P}_{\mathrm{n}}$ manifests 
event $E_{n}$. Say that $E_{1}$ is of greatest interest to person $A$, so, assuming scientific investigation works perfectly, A discovers that the "essence" of $\mathrm{x}$ is $\mathrm{P}_{1}$ and thus announces that the "real definition" of $\mathrm{x}$ is a statement about $\mathrm{P}_{1}$. Meanwhile, say that $\mathrm{E}_{2}$ is of greatest interest to person $\mathrm{B}$, so assuming scientific investigation works perfectly, B discovers that the "essence" of $\mathrm{x}$ is $\mathrm{P}_{2}$ and thus announces that the "real definition" of $\mathrm{x}$ is a statement about $\mathrm{P}_{2}$. And so on up to $\mathrm{n}$. What then is the "real definition" of $x$ ? Is it a statement entailing $P_{1}$ which ignores $P_{2} \ldots, n$ ? Or a statement entailing $P_{2}$ which ignores $P_{1,3, \ldots, n}$, and so forth. At the analytical level-that is, taking a 'view from nowhere', beyond the grasp of particular social conventions, psychological states, and the like-the particular "real definition" would be an arbitrarily chosen one. Or in other words, with nothing left but logic to guide us, we cannot but choose arbitrarily. And so we return to the underlying concern identified with nominalism to which essentialism was supposed to offer a solution. ${ }^{17}$

We can think of the versions of essentialist and nominalist approaches to meaning examined in this paper as taking diametrically opposed positions. The proponents of each, by virtue of the radical incompatibility of the two positions, remain locked in an unending struggle: each talking past the other, each claiming the other does not really understand or treat fairly their own position. By taking the meaning of a naming-term as an attempt to capture some aspect of the world-under-description, the realist side emphasises the worldunder-description, and thus meaning-intensionality, where ontologically grounded meaning determines use. In contrast, the SP side focuses its attention on the world-under-description ${ }_{2}$ and thus meaningextensionality, where socially grounded use determines meaning. Each emphasises something important and necessary to the understanding of knowledge-claims, and each, when overplaying its hand, denies what is correct in the other. Ironically, it is the over-emphasis on either the 'world' or the 'description' aspect of the 'world-under-description', which ensures that each makes distinctively different contributions to the account of the formation, change, and choice of meanings and knowledge-claims, and ironically, is also what prevents either from

\footnotetext{
${ }^{17}$ A proponent of transcendental realism might object that this misrepresents the situation, because it is not merely properties of $\mathrm{x}$ but the "constitutional or intrinsic structure" of $\mathrm{x}$ that defines $\mathrm{x}$ as a member of a natural kind (an ontological class). This will not do however, since, I submit, the very term "structure" functions as a placeholder for the selection of a limited number of apparently related properties.
} 
progressing to an acknowledgment and incorporation of the other's valuable insights.

\section{CONCLUSION}

Critique of the SP is not without its merits insofar as the SP does not give sufficient weight to non-conventional discursive and non-discursive constraints on denotation and epistemic practices. Nonetheless, the realist criticism of SP, focusing on the intensionality of meaning, has its own basic problems. Furthermore, each 'side' of this debate offers important insights into meaning-formation and change. However, since each is wedded to different and incompatible theories of meaning, each is unable to acknowledge the importance of the opposing critique. What is required, I suggest, is an approach to meaning that cuts a path between these two positions, retaining their respective strengths and abandoning their weaknesses. This task remains to be completed. While it remains incomplete, the advocates of each will remain at loggerheads, trapped in an incommensurable faux debate, where "one bare assurance is worth just as much as another" (Hegel 1977, §76, 49).

\section{REFERENCES}

Bhaskar, Roy. 1975. A realist theory of science. Leeds (UK): Leeds Books.

Bhaskar, Roy. 1979. The possibility of naturalism: a philosophical critique of the contemporary human sciences. Sussex (UK): Harvester Press.

Bhaskar, Roy. 1989. Reclaiming reality: an introduction to contemporary philosophy. London: Verso.

Bloor, David. 1976. Knowledge and social imagery. London: Routledge and Kegan Paul.

Bloor, David. 1983. Wittgenstein: a social theory of knowledge. London: Macmillan.

Bloor, David. 1991. Afterword: attacks on the strong programme. In Knowledge and social imagery, David Bloor. 1991 [1976]. Chicago: University of Chicago Press.

Bloor, David. 2007. Ideals and monisms: recent criticisms of the Strong Programme in the sociology of knowledge. Studies in the History and Philosophy of Science, 38 (1): 210-234.

Devitt, Michael. 1997 [1984]. Realism and truth. Princeton: Princeton University Press.

Giraud, Yann, and E. Roy Weintraub. 2009. Tilting at imaginary windmills: a comment on Tyfield. Erasmus Journal for Philosophy and Economics, 2 (1): 52-59.

http://ejpe.org/pdf/2-1-art-3.pdf

Hegel, Georg Wilhelm Friedrich. 1977. Phenomenology of spirit. Translated by A. V. Miller. Oxford: Oxford University Press.

Lawson, Tony. 1997. Economics and reality. London: Routledge.

Lawson, Tony. 2003. Reorienting economics. London: Routledge.

Merton, Robert K. 1973. The sociology of science: theoretical and empirical investigations. Chicago: Chicago University Press.

Mortensen, Chris. 1989. Anything is possible. Erkenntnis, 30 (3): 319-337. 
Slezak, Peter. 2000. A critique of radical social constructivism. In Constructivism in education: opinions and second opinions on controversial issues. Ninety-Ninth Yearbook of the National Society for the Study of Education, ed. D. C. Phillips. Chicago: Chicago University Press, 91-126.

Smith, Joseph Wayne. 1984. Formal logic: a degenerating research programme in crisis. Cogito, 2 (3): 1-18.

Suchting, Wallis Arthur. 1986. Marx and philosophy: three studies. London: Harvester Wheatsheaf.

Tyfield, David. 2008. The impossibility of finitism: from SSK to ESK? Erasmus Journal for Philosophy and Economics, 1 (1): 61-86. http://ejpe.org/pdf/1-1-art-3.pdf

Tyfield, David. 2009. Raging at imaginary Don-Quixotes: a reply to Giraud and Weintraub. Erasmus Journal for Philosophy and Economics, 2 (1): 60-69. http://ejpe.org/pdf/2-1-art-4.pdf

Vogel, Steven. 1996. Against nature: the concept of nature in critical theory. Albany: State University of New York Press.

Wittgenstein, Ludwig. 1973 [1953]. Philosophical investigations. Oxford: Blackwell.

Edward Mariyani-Squire is a member of the School of Economics and Finance at the University of Western Sydney, Australia. His research focuses on the philosophy of science, economic methodology and its history, and the foundations of political economy and economics. Contact e-mail: <e.mariyani-squire@uws.edu.au> 